\title{
Os Critérios de Recepção das Decisões acerca dos Delitos de Desacato do Sistema Interamericano de Direitos Humanos no Superior Tribunal de Justiça à Luz do Controle de Convencionalidade Externo
}

\author{
Criteria for Reception of Decisions on the Crimes of Contempt of the Inter- \\ American Human Rights System in the Superior Court of Justice in Light of the \\ External Conventionality Control
}

\author{
Marcelo Markus Teixeira ${ }^{1}$ \\ Reginaldo Pereira ${ }^{1}$ \\ Andrey Luciano Bieger ${ }^{1}$
}

${ }^{1}$ Universidade Comunitária da Região de Chapecó (UNOCHAPECÓ), Chapecó, SC, Brasil.

\begin{abstract}
Resumo: O artigo trata, à luz do controle de convencionalidade, da recepção da recomendação do Sistema Interamericano de Direitos Humanos de descriminalizar os crimes de desacato pelo Superior Tribunal de Justiça. Restringe-se à análise de dois recursos orientadores dos posicionamentos do Tribunal: o Recurso Especial n. 1.640.084/SP e o Habeas Corpus n. 379.269/ MS. O método é indutivo e são utilizadas a revisão bibliográfica e a análise documental como técnicas de pesquisa. Conclui-se que o Superior Tribunal de Justiça considerou apenas decisões nas quais o Estado tenha sido parte no litígio, o que descarta a recepção via mecanismo do controle de convencionalidade externo.
\end{abstract}

Palavras-chave: Desacato. Liberdade de Expressão. Controle de Convencionalidade.
Abstract: The article deals, in the light of conventional control, with the receipt of the recommendation of the Inter-American Human Rights System to decriminalize crimes of contempt by the Superior Court of Justice. The analysis is limited to two features that guide the Court's positions: Special Appeal 1,640,084/SP and Habeas Corpus 379,269/MS. The method is inductive and bibliographic review and documentary analysis are used as research techniques. It is concluded that the Superior Court of Justice considered only decisions in which the State was party to the litigation, which rules out the reception through the mechanism of external conventionality control.

Keywords: Contempt. Freedom of Expression. Conventionality Control.

Recebido em: 30/08/2018

Revisado em: 17/10/2018

Aprovado em: 24/10/2018 


\section{Introdução}

As metástases dos regimes autoritários que ocorreram na América Latina deixaram marcas de um passado que ainda não passou. Frequentemente, dispositivos legais que guardam relação com o exercício de um poder autoritário são questionados perante os mecanismos que integram o Sistema Interamericano de Direito Humanos.

Nesse cenário, importante discussão envolve os crimes de desacato e sua suposta violação ao direito à liberdade de expressão consagrado no artigo 13 da Convenção Americana de Direitos Humanos ${ }^{1}$, em razão de este ser utilizado, muitas vezes, como meio para silenciar ideias e opiniões consideradas incômodas pelo establishment.

Ainda que a ação do Sistema Interamericano ocorra, geralmente, no âmbito de suas competências contenciosa ou consultiva, consideradas apenas a partir do reconhecimento do caso pelo Estado-parte, outra proposta vem ganhando destaque: o controle de convencionalidade externo.

Nas discussões acerca da violação dos delitos de desacato ao artigo 13 da Convenção Americano de Direitos Humanos, que têm sido objeto

\footnotetext{
${ }^{1} \mathrm{O}$ artigo 13 da Convenção Americana de Direitos Humanos prevê: 1) Toda pessoa tem direito à liberdade de pensamento e de expressão. Esse direito compreende a liberdade de buscar, receber e difundir informações e ideias de toda natureza, sem consideração de fronteiras, verbalmente ou por escrito, ou em forma impressa ou artística, ou por qualquer outro processo de sua escolha. 2) O exercício do direito previsto no inciso precedente não pode estar sujeito a censura prévia, mas a responsabilidades ulteriores, que devem ser expressamente fixadas pela lei e ser necessárias para assegurar: a. o respeito aos direitos ou à reputação das demais pessoas; ou b. a proteção da segurança nacional, da ordem pública, ou da saúde ou da moral públicas. 3) Não se pode restringir o direito de expressão por vias ou meios indiretos, tais como o abuso de controles oficiais ou particulares de papel de imprensa, de frequências radioelétricas ou de equipamentos e aparelhos usados na difusão de informação, nem por quaisquer outros meios destinados a obstar a comunicação e a circulação de ideias e opiniões. 4) A lei pode submeter os espetáculos públicos a censura prévia, com o objetivo exclusivo de regular o acesso a eles, para proteção moral da infância e da adolescência, sem prejuízo do disposto no inciso 2 . 5) A lei deve proibir toda propaganda a favor da guerra, bem como toda apologia ao ódio nacional, racial ou religioso que constitua incitação à discriminação, à hostilidade, ao crime ou à violência (OEA, 2018).
} 
de questionamento nos tribunais brasileiros, o Superior Tribunal de Justiça vem uniformizando a jurisprudência a partir de dois posicionamentos, aparentemente divergentes, materializados nos julgados do Recurso Especial n. 1.640.084/SP ${ }^{2}$ e do Habeas Corpus n, 379.269/MS 3 .

Nesse contexto se insere o problema da pesquisa que ensejou o presente ensaio, que foi realizado com o intuito de responder à seguinte questão: Os critérios de recepção das decisões acerca dos delitos de desacato do Sistema Interamericano de Direitos Humanos no Superior Tribunal de Justiça respeitam o controle de convencionalidade externo? Por meio da utilização das técnicas de pesquisa bibliográfica e documental, serão analisados os critérios de recepção do Superior Tribunal de Justiça das decisões do Sistema Interamericano de Direitos Humanos em face da ideia da formação do controle de convencionalidade externo.

$\mathrm{O}$ artigo é divido em três partes. Na primeira, identificam-se os mecanismos de ação do Sistema Interamericano de Direitos Humanos, dando-se ênfase à formação do controle de convencionalidade externo. $\mathrm{Na}$ segunda parte, levanta-se a jurisprudência a respeito dos delitos de desacato no âmbito do Sistema Interamericano de Direitos Humanos. $\mathrm{Na}$ última, serão verificados, em exercício indutivo, a partir dos acórdãos dos julgados escolhidos, os critérios de recepção do Superior Tribunal de Justiça acerca das decisões que envolvem os delitos de desacato e sua suposta violação ao direito à liberdade de expressão, o que fornece o substrato para a análise destes em face da noção do controle de convencionalidade externo.

\footnotetext{
2 Superior Tribunal de Justiça. Quinta Turma. Recurso Especial n. 1.640.084/SP. Recorrente: Alex Carlos Gomes. Recorrido: Ministério Público do Estado de São Paulo. Rel. Min. Ribeiro Dantas.

${ }^{3}$ Superior Tribunal de Justiça. Terceira Seção. Habeas Corpus n. 379.269/MS. Impetrante: Defensoria Pública do Estado do Mato Grosso do Sul. Impetrado: Tribunal de Justiça do Estado do Mato Grosso do Sul. Rel. Min. Reynaldo Soares da Fonseca.
} 


\section{Os Mecanismos de Ação do Sistema Interamericano de Direitos}

A atuação de um tribunal de direitos humanos ${ }^{4}$ na América Latina assume grande importância em decorrência de a história recente de muitos países do continente ser marcada por regimes ditatoriais seguidos de jovens e instáveis democracias, dotadas de instituições, muitas vezes, omissas e vulneráveis (PIOVESAN, 2014, p. 144).

Os dois principais mecanismos de atuação do Sistema Interamericano de Direitos são a Corte Interamericana de Direitos Humanos e a Comissão Interamericana de Direitos Humanos ${ }^{5}$. Comumente, os estudos se centram no papel da Corte e são dirigidos ao exercício da via

\footnotetext{
${ }^{4}$ No âmbito do Sistema Interamericano de Proteção aos Direitos Humanos, dois órgãos exercem papel de destaque: a Corte Interamericana de Direitos Humanos e a Comissão Interamericana de Direitos Humanos. A Corte tem concentrado suas ações no âmbito da competência contenciosa, mas não se descarta a importância das opiniões consultivas emitidas, conforme o artigo $2^{\circ}$ do Estatuto da Corte. Já a Comissão, segundo o artigo 41 da Convenção Americana, tem como principais atribuições estimular a consciência dos direitos humanos nos povos da América; formular recomendações aos governos dos Estados-membros, entre outras. O Brasil aderiu a essa jurisdição quando se tornou signatário da Convenção Americana de Direitos Humanos de 1969 - Pacto de San José da Costa Rica. No entanto, a eficácia da jurisdição apenas ganhou assento no Direito brasileiro por meio do Decreto Legislativo n. 89, de 3 de dezembro de 1998, e do Decreto n. 4.463/2002, os quais reconhecem como obrigatória e por prazo indeterminado a sua jurisdição. Sendo que o instrumento só foi ratificado pelo Congresso Nacional em 1992 e promulgado pelo Decreto n. 678/1992.

${ }^{5}$ A Corte Interamericana tem desenvolvido importante papel em casos que versam sobre: a) violações que refletem o legado do regime autoritário ditatorial, as quais, além de comporem a maioria das decisões proferidas, têm por objetivo prevenir arbitrariedades e controlar o uso excessivo da força, impondo limites ao ius puniendi do Estado; b) Violações que refletem questões da justiça de transição, que guardam relação com o combate à impunidade, às leis de anistia e que garantam o direito à verdade (PIOVESAN, 2014, p. 45).
} 
contenciosa $^{6}$ ou da via consultiva ${ }^{7}$. Todavia, nesse momento, a atenção se volta ao controle de convencionalidade, que será exposto a partir de sua concretização, tanto no âmbito nacional, como no âmbito internacional, em uma acepção que vem ganhando força: a formação do controle de convencionalidade externo.

Mazzuoli (2011, p. 93) afirma que o controle de convencionalidade não é somente o exercício de compatibilidade normativa, realizado pelas instâncias internacionais de proteção dos direitos humanos, tampouco aquele que se restringe às medidas legislativas de compatibilização das leis em elaboração com os tratados internacionais, mas, sim, um meio judicial de declaração de invalidade de leis incompatíveis com os tratados, sendo auferido ou por via de exceção (controle difuso ou concreto) ou por meio de ação direta (controle concentrado ou abstrato).

A definição do controle de convencionalidade que vem ganhando força, inclusive na Corte Interamericana de Direitos Humanos, relaciona-o ao seu caráter externo. Até 2006, conforme destaca Sagüés (2017), havia o entendimento de que o controle de convencionalidade era realizado pela Corte ao reputar inválidas as normas contra a Convenção Americana sobre os Direitos do Homem. A partir desse ano, a jurisprudência da Corte inicia a construção da formação do controle de convencionalidade externo, passando a reclamar aos juízes nacionais que deixem de aplicar as normas locais que firam o Pacto de São José da Costa Rica e a sua própria jurisprudência.

\footnotetext{
${ }^{6} \mathrm{~A}$ via contenciosa é acionada por cláusulas de reconhecimento de jurisdição constantes nos artigos 61, 62 e 63 da Convenção Americana sobre Direitos Humanos. Esta via estabelece princípios e regras sobre reparações decorrentes de violações a direitos humanos pelos Estados, que figuram como demandados com responsabilidade determinada. Ao ratificar a convenção, o Estado se obriga não só a garantir, como também a prevenir e investigar, por meio de todos os recursos que dispuser, as violações à Convenção Americana (ÁVILA, 2010, p. 123; GUERRA, 2012, p. 344).

${ }^{7}$ A competência consultiva, exercida quando a Corte se manifesta nas consultas que lhe são encaminhas pelos Estados-partes, resulta na emissão de pareceres sobre a compatibilidade entre as leis internas e os instrumentos internacionais. Seu assento legal se encontra no artigo 64 da Convenção Americana de Direitos Humanos (GUERRA, 2012. p. 344).
} 
A Corte Interamericana de Direitos Humanos divide o controle de convencionalidade em dois níveis. O primeiro, chamado de controle supranacional de convencionalidade, ou controle interno - ainda que em seu início não tenha recebido essa denominação - permitiu que se declarassem como inválidas as normas de direito local que violassem a Convenção Americana de Direitos Humanos. No segundo momento, ocorrido a partir de 2006, a Corte Interamericana passou a reivindicar aos juízes nacionais que declarassem inconvencionais as normas nacionais que estivessem em desacordo com Convenção Americana de Direitos Humanos e a jurisprudência da Corte, constituindo aquilo que veio a se denominar de controle de convencionalidade externo ${ }^{8}$. O tratamento conferido pela Corte aos casos abaixo deixa transparecer as alterações em relação ao controle de convencionalidade.

O controle de convencionalidade surgiu no âmbito da Corte Interamericana de Direitos em 1994, por meio de opiniões consultivas, merecendo destaque a Opinião Consultiva OC-14/94, de 9 de dezembro de 1994 - Responsabilidad Internacional por Expedición y Aplicación de Leys Violatorias de la Convencíon, artículos $1^{\circ}$ y $2^{\circ}$, Convención Americana sobre Derechos Humanos (CIDH, 2004).

$\mathrm{O}$ valor desse julgamento se dá na medida em que a Corte conclui que a promulgação de uma lei manifestamente contrária às obrigações assumidas por um Estado ao ratificar ou aderir à Convenção constituem uma violação aos direitos e liberdades, gerando a responsabilidade internacional para o Estado. Mas foi pela via de decisões contenciosas que se fortaleceu o controle de Convencionalidade (QUINCHE RAMÍREZ, 2007, p. 175-205).

Na demanda "La Última Tentación de Cristo" - Olmedo Bustos y outros vs. Chile -, um dos casos de maior destaque, a Corte entendeu que a Constituição do Chile contrariava a Convenção Interamericana de Direitos Humanos, ao prever a censura televisiva. Os dois julgados implementaram o fundamento do respeito do Estado-Parte às normas do Pacto de São José

\footnotetext{
${ }^{8}$ Sagüés (2017) utiliza a denominação “controle de convencionalidade externo". Preferese utilizar a nomenclatura bloco de convencionalidade.
} 
da Costa Rica, fundamento principal do controle concentrado de convencionalidade exercido pela Corte (GONÇALVES, 2013, p. 398-425).

No período de novembro de 2003 a setembro de 2004, duas outras sentenças ganharam destaque: Caso Myrna Mack Chang vs. Guatemala (CIDH, 2001) e caso Tibi vs. Equador (CIDH, 2004). Nesses julgados, o juiz Sérgio García Ramirez mencionou expressamente o controle de convencionalidade, atribuindo significativa importância a ele.

No entanto, a sedimentação do controle de convencionalidade e o início do controle de convencionalidade externo se dão no julgamento do caso Almonacid Arellano e outros versus Chile (CIDH, 2006). Na sentença, a Corte faz menção expressa ao controle de convencionalidade e aos seus limites e fins:

La Corte es consciente que los jueces y tribunales internos están sujetos al imperio de la ley y, por ello, están obligados a aplicar las disposiciones vigentes en el ordenamiento jurídico. Pero cuando un Estado ha ratificado un tratado internacional como la Convención Americana, sus jueces, como parte del aparato del Estado, también están sometidos a ella, lo que les obliga a velar porque los efectos de las disposiciones de la Convención no se vean mermadas por la aplicación de leyes contrarias a su objeto y fin, y que desde un inicio carecen de efectos jurídicos. En otras palabras, el Poder Judicial debe ejercer una especie de "control de convencionalidad" entre las normas jurídicas internas que aplican en los casos concretos y la Convención Americana sobre Derechos Humanos. En esta tarea, el Poder Judicial debe tener en cuenta no solamente el tratado, sino también la interpretación que del mismo ha hecho la Corte Interamericana, intérprete última de la Convención Americana9

\footnotetext{
${ }^{9}$ A Corte é consciente que os juízes e os tribunais internos estão sujeitos ao império da lei e, por isso, estão obrigados a aplicar as disposições vigentes no ordenamento jurídico. Mas, quando um Estado tenha ratificado um tratado internacional como a Convenção Americana, seus juízes, como parte do aparato do Estado, também estão submetidos a ela, o que os obriga a zelar porque os efeitos das disposições da Convenção não prejudicam a aplicação de leis contrárias a seu objeto e fim, e que desde o início carecem de efeitos jurídicos. Em outras palavras, o Poder Judiciário deve exercer uma espécie de "controle de convencionalidade" entre as normas jurídicas internas que aplicam nos casos concretos e a Convenção Americana de Direitos Humanos. Nessa tarefa, o Poder Judiciário deve
} 
O trecho é relevante não somente por trazer a primeira menção explícita ao controle de convencionalidade no âmbito de atuação da Corte, mas também pela determinação de que os juízes nacionais observem o Pacto de São José da Costa Ricas e a jurisprudência da Corte Interamericana, no exercício do controle de convencionalidade.

No caso Trabajadores Cesados del Congresso (Aguado Algaro y outros) versus Peru (CIDH, 2006) há uma complementação sobre o papel do controle de convencionalidade. Nele, define-se que o controle de convencionalidade deve ser aplicado pelos juízes nacionais, de ofício, sem a necessidade de pedido de uma das partes.

A ideia de formação do controle de convencionalidade externo ganha força e passa a ser citada, dessa vez, com nominação de "bloco da convencionalidade"10, no caso Ibsen Cárdenas e Ibsen Peña versus Bolívia (CIDH, 2010), com nova menção de observância expressa à jurisprudência da Corte.

Ao julgar o caso Teodoro Cabrera García e Rodolgo Montiel Flores versus México, a Corte Interamericana de Direitos Humanos (2010) mencionou, de forma expressa, a figura do bloco de convencionalidade:

El desarrollo descrito de incorporación del derecho internacional de los derechos humanos en sede nacional, también se debe a las propias jurisdicciones domésticas, especialmente a las altas jurisdicciones constitucionales, que progresivamente han privilegiado interpretaciones dinámicas que favorecen y posibilitan la recepción de los derechos humanos previstos en los tratados internacionales. Se forma un auténtico bloque de constitucionalidad, que si bien varía de país a país, la tendencia es considerar dentro del mismo no sólo a los derechos humanos previstos en los pactos internacionales, sino también a la propia jurisprudencia de la Corte IDH. Así, en algunas ocasiones el bloque de convencionalidad queda subsumido

levar em conta não apenas o tratado, mas também a interpretação de que ele recebe da Corte Interamericana, intérprete última da Convenção Americana (CIDH, 2006).

${ }^{10}$ A noção do bloco de convencionalidade guarda relação com o controle de convencionalidade externo, todavia, a noção de bloco de convencionalidade pode ser ainda mais ampla (SAGÜÉS, 2017; MAZZUOLI, 2011). 
en el bloque de constitucionalidad, por lo que al realizar el control de constitucionalidad también se efectúa control de convencionalidad.

O trecho reforça o entendimento da Corte de atrelar os juízes ao Pacto de São José da Costa Rica e à interpretação que a Corte confere ao Pacto. Dessa forma, o controle de convencionalidade externo, no âmbito do Sistema Interamericano de Proteção dos Direitos Humanos, pode ser entendido como um conjunto de normas materiais e formais do Pacto de San José da Costa Rica, as quais servem como parâmetro para a análise da compatibilidade de uma norma nacional para a garantia de proteção dos direitos humanos (GONÇALVES, 2013, p. 4.150). A impossibilidade de aplicação de interpretação convencional suspende os efeitos da norma nacional e possibilita a aplicação de efeitos gerais ou particulares, a depender dos poderes do juiz que realiza o controle (BENAVANTE CHORRES, 2012, p. 171).

Tal obrigação - inaplicabilidade de normas que violam a Convenção Americana de Direitos Humanos ou da Jurisprudência da Corte - não tem respaldo em nenhum dispositivo da Convenção, ela decorre da interpretação conferida pela Corte com vistas ao fortalecimento do Sistema Interamericano de Direitos Humanos que está fundamentada em três argumentos básicos: i) no princípio da boa fé no cumprimento das obrigações internacionais; ii) no princípio do útil das Convenções; e iii) no artigo 27 da Convenção de Viena sobre o Direito dos Tratados, que impede a um Estado invocar as disposições de seu direito interno para justificar o inadimplemento de um tratado (SAGÜÉS, 2017).

Com efeito, a formação do controle de convencionalidade externo acaba conferindo papel de maior de destaque à jurisprudência da Corte, fazendo com que a aplicação do direito interno se dê em conformidade com os enunciados por ela proferidos. 


\section{C Conflito entre o Direito à Liberdade de Expressão e os Cri- mes de Desacato na Jurisprudência do Sistema Interamerica- no de Direitos Humanos}

O ponto central das discussões sobre a convencionalidade dos crimes de desacato orbita em torno da violação desses delitos ao direito de liberdade de expressão ${ }^{11}$.

No âmbito do Sistema Interamericano de Direitos Humanos, a liberdade de expressão encontra ampla proteção na Convenção Americana de Direitos Humanos, a qual inclui, dentro desse direito, a liberdade de buscar, receber e difundir informações e ideias de toda natureza.

O primeiro caso a veicular o embate foi o do jornalista Horácio Verbitsky versus Argentina. No dia 6 de março de 1988, o jornalista publicou um artigo intitulado "Cicatrices de las Guerras", no qual adjetivou o então Ministro da Suprema Corte de Justiça da República Argentina, Augusto Belluscio, de "asqueroso" por ter manifestado em uma entrevista o interesse em ampliar a Corte Suprema com dois Ministros adicionais. Com a publicação desse artigo, iniciou-se um processo que resultou na condenação do jornalista pelo crime de desacato.

Como resolução da controvérsia, houve a composição amistosa (artigo 48, alínea f, da Convenção Americana de Direitos Humanos ${ }^{12}$ ) e a Argentina assumiu o compromisso de retirar do seu ordenamento o delito de desacato.

\footnotetext{
${ }^{11}$ Os delitos de desacato são tipificados pelo ato de desacatar, verbo que guarda certa vagueza e que, geralmente, é associado a condutas de desrespeitar, ofender, menosprezar, por meio de qualquer palavra ou ato, podendo ser atribuída até a grosseira falta de acatamento e a gestos obscenos ou a qualquer palavra ou ato que redunde em vexame, humilhação, desprestígio ou irreverência ao funcionário público (BITENCOURT, 2012, p. 357; HUNGRIA, 1942, p. 424).

${ }^{12}$ Segundo o artigo 48, alínea $\mathrm{f}$ da Convenção Americana de Direitos Humanos, a “[...] Comissão, ao receber uma petição ou comunicação na qual se alegue a violação de qualquer dos direitos consagrados na Convenção, procederá da seguinte maneira: [...]; f) pôr-se-á à disposição das partes interessadas, a fim de chegar a uma solução amistosa do assunto, fundada no respeito aos direitos reconhecidos nesta Convenção.
} 
Alguns anos depois, a Comissão Interamericana de Direitos Humanos formulou o Relatório Especial de 1995, no qual afirmou que as leis de desacato se prestam ao abuso, como meio para silenciar ideias e opiniões consideradas incômodas pelo establishment, além de proporcionam maior nível de proteção aos agentes do Estado que aos particulares, em contravenção aos princípios democrático e igualitário (CIDH, 1995).

Em outro caso, Palamara-Iribarrne versus Chile (CIDH, 2005), a Corte considerou que o Chile violou o disposto no artigo 13 da Convenção, que garante a toda pessoa o direito à liberdade de pensamento e de expressão, ante a imputação de crime de desacato ao escritor Humberto Antonio Palamara-Iribarne.

Em 1993, Humberto Antônio Palamara-Iribarne teria, segundo a justiça chilena, atentado contra a segurança e a defesa nacional, por ter publicado o livro Ética y Servicios de Inteligencia, que trata da necessidade de articular a inteligência militar a parâmetros éticos. A publicação do livro foi proibida e o escritor foi condenado pelos delitos de desobediência e desacato.

O Chile havia reformado a legislação que tipificava o crime de desacato, ligando-o à figura da ameaça.

A Corte Interamericana de Direitos Humanos condicionou a manutenção da norma pelo Estado-Parte à densificação conceitual do tipo penal pela explicitação de que tipo de ameaça se trata, de forma tal que não se reprima a liberdade de pensamento e de expressão de opiniões legítimas e legais ou quaisquer inconformidades e protestos acerca da atuação dos órgãos e agentes públicos (CDHI, 2005).

No caso Ríos y otros versus Venezuela (CDHI, 2009), submetido pela Comissão Interamericana à Corte em 26 de outubro de 2006, foram analisados quarenta episódios de violação ao direito de liberdade de expressão, ocorridos na Venezuela de janeiro de 2001 a junho de 2004, período em que o país atravessou uma crise institucional.

Segundo o Estado Venezuelano, os meios de comunicação, por meio de uma campanha midiática voraz, causaram um levante popular. Além dis- 
so, o governo da Venezuela acusava a rede de televisão RCTV de ter participado do golpe que tentou derrubar o Presidente Hugo Chávez.

Em janeiro de 2009, a Corte Interamericana de Direitos Humanos decidiu o caso. A sentença menciona diferentes atos públicos e privados que restringiram a atuação jornalística dos trabalhadores, dirigentes e demais pessoas relacionadas ao canal televisivo RCTV, assim como a alguns discursos de atores estatais contra o meio de comunicação. A Corte Interamericana estabeleceu que tais discursos, potencialmente intimidadores, eram incompatíveis com a liberdade de buscar, receber e difundir informações. A Corte reiterou sua doutrina sobre as restrições indiretas à liberdade de expressão e ordenou ao Estado da Venezuela conduzir de modo eficaz as investigações e processos penais por atos de violência contra os jornalistas, bem como a adotar medidas necessárias para evitar restrições indevidas e obstáculos diretos ou indiretos ao exercício da liberdade de buscar, receber e difundir informações (OEA, 2018).

O caso Ivcher Bronstein versus Peru (CIDH, 2001) versou sobre a perda da nacionalidade peruana de Ivcher Bronstein, durante o governo de Alberto Fujimori. Bronstein era sócio de uma rede televisiva que fez denúncias, por meio de reportagens, das torturas cometidas pelos membros do Serviço de Inteligência do Exército do Peru. No julgamento do caso, a Corte entendeu que o Estado Peruano violou, entre outros, o artigo 13 do Pacto de San José da Costa Rica, e determinou o retorno da nacionalidade, uma vez que a sua revogação se constitui em meio indireto de restrição à liberdade de expressão ${ }^{13}$.

No caso Tristán Danoso versus Panamá (CIDH, 2009), a demanda se referia à interceptação, gravação e divulgação de uma conversa telefônica envolvendo o advogado Santander Tristán Danoso, que resultou em abertura de processo penal por delitos contra a honra, como forma de represália às denúncias feitas pelo advogado. Na sentença, a Corte entendeu

\footnotetext{
${ }^{13} \mathrm{O}$ artigo 13/3 da Convenção Interamericana de Direitos Humanos veda a restrição do direito de expressão por vias e meios indiretos, tais como o abuso de controles oficiais ou particulares de papel de imprensa, de frequências radioelétricas ou de equipamentos e aparelhos usados na difusão de informação, nem por quaisquer outros meios destinados a obstar a comunicação e a circulação de ideias e opiniões (CIDH, 2018).
} 
que, por meio das sanções impostas a Tristán Danoso, o Estado restringiu o direito à liberdade de pensamento e de expressão, consagrado no artigo 13 da Convenção Americana de Direitos Humanos.

A Corte analisou outros casos e manteve o entendimento da necessária convivência entre a vigência de uma ordem democrática e a liberdade de expressão, em sua dupla dimensão: a individual e a social, assegurando ao indivíduo o direito de expressar e difundir suas ideias, bem como, à coletividade, o direito de acessar informações e conhecer a opinião alheia (FALSARELLA, 2012, 127-148).

É possível encontrar no julgamento de outros casos, a preocupação do Sistema Interamericano com a coibição causada pelos crimes de desacato à liberdade de expressão.

No Caso Blake versus Guatemala, julgado em 2001 pela Corte (CIDH, 2001), que envolve o sequestro e o assassinato de Nicholas Blacke por Agentes do Estado da Guatemala, a Corte, apesar de não analisar diretamente o embate entre a liberdade de expressão e o desacato, reconheceu a intensa relação entre a liberdade de expressão e a democracia. Tal fundamento também foi reconhecido no caso La Última Tentación de Cristo, analisado anteriormente.

$\mathrm{O}$ caso Ricardo Canese, candidato às eleições presidenciais do $\mathrm{Pa}-$ raguai de 1993 e que durante os debates eleitorais fez críticas à suposta corrupção ocorrida na construção da usina hidrelétrica de Itaipu e ao enriquecimento ilícito do ditador paraguaio Alfredo Stroessner, versus Paraguai envolveu o direito à liberdade de expressão em seu aspecto de difundir ideias e pensamentos (CIDH, 2004).

No período pré-eleitoral, Ricardo Canese questionou a idoneidade do candidato Juan Carlos Wasmosy, o qual teria enriquecido graças ao fato de ter sido presidente da CONEMPA (Consórcio de Empresas Construtoras Paraguaias), detentora das principais obras de Itaipu. Ao analisar o mérito da questão, a Corte destacou a prevalência da dimensão individual e social da liberdade de expressão, destacando a sua importância em uma sociedade democrática (FALSARELLA, 2012, p. 127-148). 
Da análise desses casos, percebe-se que, em que pese o direito à liberdade de expressão não ter caráter absoluto, existe formação jurisprudencial favorável ao tratamento dos crimes de desacato como mecanismos de violação do direito à liberdade de expressão e que tal entendimento, de acordo com o entendimento da Corte Interamericana de Direitos Humanos, está lastreado na ofensa que representam ao artigo 13 da Convenção Americana de Direitos Humanos.

Corroborando o entendimento da Corte, a Comissão Interamericana de Direitos Humanos (2017), em seu $108^{\circ}$ período ordinário de sessões, realizado de 16 a 27 de outubro de 2000, aprovou a Declaração de Princípios sobre Liberdade de Expressão, que estatui entre outros, o princípio que sujeita os funcionários públicos a um maior controle por parte da sociedade e estabelece que punições à manifestação ofensiva dirigida a funcionários públicos, geralmente conhecida como leis de desacato, atentam contra a liberdade de expressão e o direito à informação.

Resta verificar como o Brasil vem recepcionando as decisões da Corte Interamericana de Direitos Humanos.

\section{Critérios de Recepção das Decisões Proferidas no Âmbito do Sistema Interamericano de Direitos Humanos acerca dos Deli- tos de Desacato no Superior Tribunal de Justiça}

No Brasil, a discussão acerca da violação dos que os delitos de desacato representam à liberdade de expressão e ao direito à informação ganhou destaque a partir do momento em que a matéria passou a ser analisada pelo Superior Tribunal de Justiça. Entre as decisões acerca do tema, duas merecem atenção: o Recurso Especial n. 1.640.084/SP e o Habeas Corpus n. 379.269/MS. Os dois processos apresentam soluções antagônicas quanto à recepção do posicionamento da Corte Interamericana de Direitos Humanos e, por isso, acabam balizando as demais decisões do gênero, tanto as favoráveis à descriminalização do delito de desacato, quanto as contrárias. 
No Recurso Especial n. 1.640.084/SP (STJ, REsp n. 1.640.084/SP, 2016), de Relatoria do Ministro Ribeiro Dantas, julgado pela Quinta Turma, houve a declaração da inconvencionalidade do artigo 331 do Código Penal ${ }^{14}$. No caso, a Turma entendeu, com base em solução adotada no Recurso Extraordinário n. 466.343/SP do Supremo Tribunal Federal e no Recurso Especial n. 914.253/SP ${ }^{15}$, que o dispositivo em questão estaria invalidado, não revogado, pois a punição à utilização de "[...] linguagem e atitudes ofensivas contra agentes estatais é medida capaz de fazer com que as pessoas se abstenham de usufruir do direito à liberdade de expressão, por termo de sanções penais[...]”. (STJ, REsp n. 1.640.084/SP, 2016).

A respeito do critério de recepção, nesse caso, prevaleceu o entendimento de que os tratados de direitos humanos ratificados pelo país possuem força supralegal, isto é, a lei que violar o conteúdo de tratados internacionais sobre direitos humanos não possui validade, o que leva à declaração da inconvencionalidade do delito de desacato em razão da sua violação ao direito à liberdade de expressão. A decisão levou em consideração julgados da Corte Interamericana de Direitos Humanos e recomendações da Comissão Interamericana de Direitos Humanos, ainda que não tenha considerado explicitamente e aplicado o mecanismo de controle de convencionalidade externo.

A questão ganhou outros contornos no julgamento do Habeas Corpus n. 379.269/MS (STJ, HC n. 379.269/MS, 2017). Ao julgar a ação, a Terceira Seção do Tribuna ${ }^{16}{ }^{16}$ decidiu que o crime de desacato, conforme

\footnotetext{
${ }^{14}$ A redação do artigo 331 do Código Penal é: Desacatar funcionário público no exercício da função ou em razão dela: Pena - detenção, de seis meses a dois anos, ou multa.

${ }^{15}$ Estes recursos assentaram as bases no sentido de indicar que os tratados de direitos humanos, ratificados pelo país, possuem força supralegal, isto é, a lei que violar o conteúdo de tratados internacionais sobre direitos humanos não possui validade. (STF, RE n. 466.343/SP, 2008; STJ, REsp n. 914.253/SP, 2009).

${ }_{16}$ Segundo o Regimento Interno do Superior Tribunal de Justiça, artigo $8^{\circ}$, § $3^{\circ}$ : “À Terceira Seção cabe processar e julgar os efeitos relativos à matéria penal em geral, salvo os casos de competência originária da Corte Especial e os habeas corpus de competência das Turmas que compõem a Primeira e a Segunda Seção". Por sua vez, as competências da Seção estão enumeradas no artigo 12 do Regimento Interno do Superior Tribunal de Justiça. A Quinta e a Sexta turma integram a Terceira Seção, que possui competência para a apreciação de matéria criminal (SUPERIOR TRIBUNAL DE JUSTIÇA, 2018).
} 
previsto no artigo 331 do Código Penal não viola o artigo 13 da Convenção Americana de Direitos Humanos.

A decisão foi fundamentada na premissa da relatividade do direito à liberdade de expressão, em função do teor do artigo $13 / 2^{17}$ do Pacto de San José da Costa Rica, fato que possibilita a sua restrição. A maioria dos membros da Terceira Seção contrariou o voto do relator, Ministro Reynaldo Soares da Fonseca, que havia fundamentado sua decisão no voto proferido pelo Ministro Ribeiro Dantas no julgamento do Recurso Especial n. 1.640.084/SP e, por isso, concedeu a ordem de ofício para declarar a inconvencionalidade do delito de desacato e retirá-lo da ação penal que tramitava em desfavor do réu.

Fato que chama atenção, para os objetivos do presente artigo, é a afirmação de que o Controle de Convencionalidade pode ser apenas aplicado em casos semelhantes aos levados à Corte Interamericana de Direitos Humanos, em detrimento dos posicionamentos da Comissão Interamericana de Direitos Humanos.

Isso, porque, conforme o voto vencedor proferido pelo Ministro Reynaldo Soares da Fonseca, o artigo 41 do Pacto de San José da Costa Rica confere à Comissão Interamericana de Direitos Humanos a função primordial de promover a observância e a defesa dos direitos humanos, não suscitando, assim, caráter decisório, mas somente instrutório ou cooperativo.

Em outros termos, a Comissão não possui função jurisdicional. Tal papel cabe à Corte Interamericana de Direitos Humanos que detém a competência jurisdicional para aplicar e interpretar a Convenção

\footnotetext{
${ }^{17}$ De acordo com o artigo 13/2 da Convenção Interamericana de Direitos Humanos, o exercício do direito à liberdade de expressão não pode estar sujeito à censura prévia, mas a responsabilidades ulteriores, que devem ser expressamente previstas em lei e que se façam necessárias para assegurar: a) o respeito dos direitos e da reputação das demais pessoas; b) a proteção da segurança nacional, da ordem pública, ou da saúde ou da moral públicas.
} 
Americana dos Diretos Humanos, conforme prescreve o artigo $2^{\circ}$ do seu Estatuto $^{18}$.

Assim, segundo interpretação conferida pelo Ministro Reynaldo Soares da Fonseca, por força do artigo 68 da Convenção Americana de Direitos Humanos, somente as decisões da Corte são dotadas de caráter vinculante aos Estados partes.

Deve ser destacado que, ainda fazendo menção ao caso Cabrera Garcái y Montiel Flores versus México, o que daria suporte ao controle de convencionalidade externo, em seu voto, o Ministro Rogério Schietti Cruz conclui que a situação fática do Habeas Corpus n. 396.279/MS era diferente daquela apresentada pelos casos levados à Corte Interamericana de Direitos Humanos para julgamento, os quais, invariavelmente, estavam relacionados à jornalistas ou escritores.

Esse fator leva o Ministro a concluir que, em razão do Brasil não ter sido condenado em nenhum caso com matéria afetada aos casos discutidos pela Corte Interamericana de Direitos Humanos, não há como se ordenar a descriminalização do desacato.

Tais motivos permitem concluir que o Superior Tribunal de Justiça recepciona apenas as decisões acerca dos delitos de desacato do Sistema Interamericano de Direitos Humanos nas quais o Estado tenha sido parte no litígio, desconsiderando, ainda, recomendações emanadas pela Comissão Interamericana de Direitos Humanos.

\section{Conclusão}

A identificação dos mecanismos de ação do Sistema Interamericano de Direitos Humanos, em especial, a formação do controle de convencionalidade externo sugere que um Estado signatário da Convenção Americana de Direitos Humanos confira especial atenção ao tratamento dado

\footnotetext{
${ }^{18}$ Conforme o artigo $2^{\circ}$ de seu Estatuto, a Corte Interamericana de Direitos Humanos exerce função jurisdicional e consultiva. Sua função jurisdicional se rege pelas disposições dos artigos 61, 62 e 63 da Convenção. Sua função consultiva se rege pelas disposições do artigo 64 da Convenção (CIDH, 2018).
} 
pela Corte Interamericana de Direitos Humanos aos direitos previstos na Convenção e aplique o direito interno em conformidade com os enunciados por ela proferidos.

Tal constatação aumenta a relevância das decisões proferidas no âmbito do Sistema Interamericano de Proteção aos Direitos Humanos, uma vez que o levantamento da jurisprudência a respeito dos delitos de desacato indica que existe uma tendência jurisprudencial em considerar que tais delitos violam o artigo 13 da Convenção Americana de Direitos Humanos em razão da sua vagueza conceitual.

Da identificação dos critérios de recepção das decisões acerca dos delitos de desacato do Sistema Interamericano de Direitos Humanos pelo Superior Tribunal de Justiça vê-se o posicionamento no sentido de adotar apenas decisões nas quais o Estado tenha sido parte no litígio, ignorando, ainda, qualquer posicionamento emanado pela Comissão Interamericana de Direitos Humanos e de outros julgados emitidos pela Corte Interamericana de Direitos Humanos.

Com efeito, a análise do Recurso Especial n. 1.640.084/SP e, em especial, a do Habeas Corpus n. 379.269/MS, demonstra que o Superior Tribunal de Justiça recepciona decisões acerca dos delitos de desacato, proferidas pela Sistema Interamericano de Direitos Humanos somente nos casos em que o Estado tenha sido parte no litígio, desconsiderando, assim, a ideia do controle de convencionalidade externo.

\title{
Referências
}

\begin{abstract}
ÁVILA, Flávia de; NOLASCO, Tiago Junqueira Nolasco. Efectividad de las decisiones de la Corte Interamericana de Derechos Humanos em Brasil. Revista Logos Ciência \& Tecnología, [S.l.], v. 2, n. 1, p. 121135, jul./dez., 2010.
\end{abstract}

BENAVANTE CHORRES, Hesbert. El juez de control como garante de la convencionalidad de las normas em el nuevo processo penal mexicano. Estudios Constitucionales, [S.l.], Ano. 10, v. 1. p. 145-200, 2012. 
BITENCOURT, Cezar Roberto. Tratado de Direito Penal Parte Especial 5. São Paulo: Ed. Saraiva, 2012.

BRASIL. Código Penal. Decreto-lei n. 2.848, de 7 de dezembro de 1940. Disponível: http://www.planalto.gov.br/ccivil_03/decreto-lei/del2848. htm. Acesso: 15 jul. 2015.

. Decreto Legislativo n. 89, de 3 de dezembro de 1998.

Disponível em: http://www2.camara.leg.br/legin/fed/decleg/1998/ decretolegislativo-89-3-dezembro-1998-369634-publicacaooriginal-1-pl. html. Acesso em: 17 jul. 2018.

. Decreto n. 4.463/2002, de 3 de dezembro de 1998. Disponível em: http://www2.camara.leg.br/legin/fed/decret/2002/decreto-4463-8novembro-2002-485986-publicacaooriginal-1-pe.html. Acesso em: 17 jul. 2018.

. Decreto n. 678, de 6 de novembro de 1992. Disponível em: http://www.planalto.gov.br/ccivil_03/decreto/d0678.htm. Acesso em: 17 jul. 2018.

CIDH - CORTE INTERAMERICANA DE DIREITOS HUMANOS.

Blake versus Guatemala. Sentença de 24 de janeiro de 1998. Disponível em: www.corteidh.or.cr/docs/casos/articulos/seriec_36_esp.pdf . Acesso em: 9 ago. 2017.

. Canese versus Paraguai. Sentença de 31 de agosto de 2004. Disponível em: www.corteidh.or.cr/docs/casos/articulos/seriec_111_esp. pdf . Acesso em: 9 ago. 2017.

. Caso "La Última Tentación de Cristo" (Olmedo Bustos y otros) versus Chile. Fondo, Reparaciones y Costas. Sentencia de 5 de febrero de 2001. Serie C n. 73. Disponível em: http:/www.corteidh.or.cr/ docs/casos/articulos/Seriec_73_esp.pdf. Acesso em: 28 jul. 2017.

. Caso Almonacid Arellano y outros versus Chile. Expceciones Preliminares, Fondo, Reparaciones y Costas. Sentencia de 26 de septiembre de 2006. Serie C n. 154. Disponível em: http://www.corteidh. or.cr/docs/casos/articulos/seriec_154_esp.pdf . Acesso em: 28 jun. 2017. 


\section{. Caso Cabrera García y Montiel Flores versus México.}

Excepción Preliminar, Fondo, Reparaciones y Costas. Sentencia de 26 de noviembre de 2010 Serie C n. 220. Disponível em: http://www.corteidh. or.cr/docs/casos/articulos/seriec_220_esp.pdf. Acesso em: 29 jun. 2017.

Caso Ibsen Cárdenas e Ibsen Penã versus Bolivia. Fondo, Reparaciones y Costas. Sentencia de $1^{\circ}$ de septiembre de 2010 Serie C. n. 217. Disponível em: http://www.corteidh.or.cr/docs/casos/articulos/ seriec_217_esp1.pdf. Acesso em: 28 jun. 2017.

. Caso Palamara Iribarne versus Chile. Sentença de 22 de novembro de 2005. Disponível em: www.corteidh.or.cr/docs/casos/ articulos/seriec_135_esp.pdf. Acesso em: 6 jul. 2017.

Caso Tibi versus Equador. Excepciones Preliminares, Fondo, Reparaciones y Costas. Sentencia de 7 de septiembre de 2004. Serie C n. 114. Disponível em: www.corteidh.or.cr/docs/casos/articulos/seriec_114 esp.pdf . Acesso em: 28 jun. 2017.

. Ivcher Bronstein versus Perú. Interpretación de la Sentencia de Fondo. Sentencia de 4 de septiembre de 2001. Serie C n. 84. Disponível em: www.corteidh.or.cr/docs/casos/articulos/Seriec_74_esp.pdf . Acesso em: 5 jul. 2017.

. Myrna Mack Chang versus Guatemala. CORTE IDH. Caso Myrna Mack Chang versus Guatemala. Fondo, Reparaciones Y Costas. Sentencia de 25 de noviembre de 2003. Serie C n. 101. Disponível em: http://www.corteidh.or.cr/docs/casos/articulos/seriec_101_esp.pdf . Acesso em: 28 jun. 2017.

Ríos e outros versus Venezuela. Sentença de 28 de janeiro de 2009, p. 46-47. Disponível em: http://corteidh.or.cr/docs/casos/articulos/ seriec_194_esp.pdf. Acesso em: 5 jul. 2017.

\section{. Trabajadores Cesados del Congresso (Aguado Algaro y}

outros) versus Perú. Excepciones Preliminares, Fondo, Reparaciones y Costas. Sentenccia de 25 de Noviembre de 2006. Serie C n. 158. Disponível em: http://www.corteidh.or.cr/docs/casos/articulos/ seriec_174_esp.pdf. Acesso em: 29 jun. 2017. 
. Tristán Dano versus Panamá. Sentença de 27 de fevereiro de 2009. Disponível em: http://www.corteidh.or.cr/docs/casos/articulos/ seriec_193_esp.pdf. Acesso em: 5 jul. 2017.

COMISSÃO INTERAMERICANA DE DIREITOS HUMANOS. Relatório sobre a compatibilidade entre as leis de desacato e a Convenção Americana sobre Direitos Humanos. OEA/SER. L/V/ II.88M, doc. 9 ver., 19 de fevereiro de 1995.

. Informativo n. 22/94, Caso 11.012. Comissão Interamericana de Direitos Humanos. OEA. 1994.

. Declaração de Princípios Sobre Liberdade de Expressão.

17 a 27 de outubro de 2000. Disponível em: https://www.cidh.oas.org/ basicos/portugues/s.Convencao.Libertade.de.Expressao.htm . Acesso em: 15 jul. 2017.

\section{. Relatório Especial para la Libertad de Expresión.}

2016. Disponível em: www.cidh.oas.org/relatoria/ShowDocument. asp?DocumentID=139 . Acesso em: 8 jul. 2017.

FALSARELLA, Christiane Mina. A liberdade de expressão na Jurisprudência da Corte Interamericana de Direitos Humanos. n. 61. p. 127-148, 2012.

GONÇALVES, Vinicius de Almeida. A Figura do Bloco de Convencionalidade nas decisões proferidas pela corte interamericana de direitos humanos. Revista Eletrônica do Curso de Direito, Santa Maria, RS, UFSM, v. 8, n. 2, p. 398-425, 2013.

GUERRA, Sidney. A proteção internacional dos direitos humanos no âmbito da Corte Interamericana e o Controle de Convencionalidade. Revista Nomos, [S.l.], v. 32, n. 2, p. 341-366, jul./dez., 2012.

HUNGRIA, Nélson. Comentários ao Código Penal. Rio de Janeiro, Forense, 1942.

MAZZUOLI, Valerio de Oliveira. O Controle Jurisdicional da Convencionalidade das Leis. São Paulo: Ed. Revista dos Tribunais, 2011. p. 93. 
OEA. Comissão Interamericana de Direitos Humanos. Informativo n. 22/94. Caso 11.012. Comissão Interamericana de Direitos Humanos. OEA. 1994. Disponível em: https://www.cidh.oas.org/annualrep/94eng/ Argentina11012.htm . Acesso em: 15 jul. 2017.

. Convenção Americana de Direitos Humanos. Pacto de São José da Costa Rica, de 22 de novembro 1969. Disponível em: https:// www.cidh.oas.org/basicos/portugues/c.convencao_americana.htm . Acesso em: 15 jul. 2017.

PIOVESAN, Flávia. Direitos humanos e o direito constitucional internacional. 13. ed. São Paulo: Saraiva, 2012. p. 94.

. Sistema Interamericano de Direitos Humanos: impacto transformador, diálogos jurisidiconais e os desafios da reforma. Revista de Estudos Constitucionais, Hermenêutica e Teoria do Direito (RECHTD), [S.l.], v. 6. n. 2. p. 42-154, jul./set., 2014.

QUINCHE RAMÍREZ, Manuel Fernando. El control de constitucionalidad y el control de convencionalidad. Revista Centro de Estudios Políticos, [S.l.], v. 1, p. 175-205, 2009.

SAGÜÉS, Néstor Pedro. El "control de convencionalidad" em el sistema interamericano, y sus anticipios em el âmbito de los derechos econômicos-socialies. Concordancias y diferencias com el sistema europeo. Biblioteca jurídica virtual del instituto de investigaciones jurídicas de la UNAM. Disponível em: http://biblio.juridicas.unam.mx/ libros/7/3063/16.pdf. Acesso em: 29 jun. 2017.

SUPERIOR TRIBUNAL DE JUSTIÇA. Quinta Turma. Recurso Especial n. 1.640.084/SP. Recorrente: Alex Carlos Gomes. Recorrido: Ministério Público do Estado de São Paulo. Rel. Min. Ribeiro Dantas. 16 de dez. de 2016.

. Terceira Sessão. Habeas Corpus n. 379.269/MS. Impetrante: Tribunal de Justiça do Estado de Mato Grosso do Sul. Impetrado: Tribunal de Justiça do Estado de Mato Grosso do Sul. Paciente: Magno Leandro Santos Angelico. Rel. Min. Reynaldo Soares da Fonseca. 24 de maio de 2017. 
Marcelo Markus Teixeira é doutor em Direito Internacional Privado pela Universität zu Köln. Professor do Programa de Pós-Graduação em Direito da Unochapecó. Pesquisador do Grupo de Pesquisa Direito, Democracia e Participação Cidadã certificado pela Unochapecó.

E-mail: marcelomarkus@unochapeco.edu.br

Endereço profissional: Rua Senador Attilio Fontana, 591-E, Efapi, Chapecó, SC. CEP: 89809-000.

Reginado Pereira é doutor em Direito pela Universidade Federal de Santa Catarina. Professor e Coordenador do Programa de Pós-Graduação em Direito da Unochapecó. Líder do Grupo de Pesquisa Direito, Democracia e Participação Cidadã certificado pela Unochapecó.

E-mail: rpereira@unochapeco.edu.br

Endereço profissional: Rua Senador Attilio Fontana, 591-E, Efapi, Chapecó, SC. CEP: 89809-000.

Andrey Luciano Bieger é mestre em Direito no Programa de Pós-Graduação em Direito da Unochapecó. Bolsista Capes. Pesquisador do Grupo de Pesquisa Direito, Democracia e Participação Cidadã certificado pela Unochapecó.

E-mail: andreybieger@hotmail.com

Endereço profissional: Rua Senador Attilio Fontana, 591-E, Efapi, Chapecó, SC. CEP: 89809-000. 